\title{
Photocatalytic asphalt mixtures: Mechanical performance and impacts of traffic and weathering abrasion on photocatalytic efficiency
}

\author{
Iran Gomes da Rocha Segundo ${ }^{\mathrm{a}}$, Salmon Landi Jr. ${ }^{\mathrm{b}, \mathrm{c}}$, Sérgio Manuel Batista Oliveira ${ }^{\mathrm{a}}$, \\ Elisabete Fraga de Freitas ${ }^{a}, *$, Joaquim Alexandre O. Carneiro ${ }^{c}$

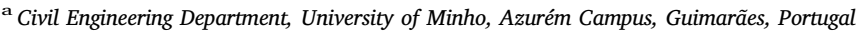 \\ ${ }^{\mathrm{b}}$ Instituto Federal Goiano, Rio Verde, GO, Brazil \\ ${ }^{c}$ Physics Department, University of Minho, Azurém Campus, Guimarães, Portugal
}

\section{A R T I C L E I N F O}

\section{Keywords:}

Functionalization

Photocatalysis

Asphalt mixtures

Water

Traffic wearing

Mechanical performance

\begin{abstract}
A B S T R A C T
The photocatalytic asphalt mixture provides safer roads and mitigates the air quality problems, trapping and degrading organic compounds and also harmful gases. In this research, an asphalt mixture was functionalized with nano- $\mathrm{TiO}_{2}$ by bulk incorporation, using the contents 3 and $6 \%$, and by spraying coating using an aqueous solution over its surface at different temperatures and rates. For bulk incorporation, the mechanical performance was assessed. The factors - application procedure, influence of temperature, spraying rate, incorporation percentage and $\mathrm{TiO}_{2}$ immobilization (from traffic and rain removal) - were evaluated based on Rhodamine $\mathrm{B}$ (RhB) degradation. For bulk incorporation, the best content nano- $\mathrm{TiO}_{2}$ was $3 \%$. The temperature of the substrate has no influence on the photocatalytic results. The most effective spraying rates were 8 and $16 \mathrm{~mL} / \mathrm{cm}^{2}$. Before simulating the traffic effect, the spraying coating technique was more effective than the bulk incorporation one. After this process, the opposite behaviour was detected. The rain simulation did not cause removal of the nanoparticles. Additionally, the exposed aggregates affected the photocatalytic efficiency, being important their contribution combined to the effect of nano- $\mathrm{TiO}_{2}$. To have the maximum benefit of the techniques studied, the ideal solution would be the combination of both, with negligible impact on mechanical performance.
\end{abstract}

\section{Introduction}

The emission of the contaminants into the atmosphere is one of the biggest concerns in the world nowadays. In general, transportation sector and industrial activities are the main sources that damage air quality. Namely, nitrogen oxides $\mathrm{NO}_{\mathrm{x}}$ (mainly $\mathrm{NO}$ and $\mathrm{NO}_{2}$ ) and volatile organic compounds, which are among the most dangerous, can increase the risk of respiratory problems [1]. Therefore, it is highly desirable to reduce, at least, the disposal of these pollutants. However, in the current stage of the society, the use of treatment methods that enable the reduction of pollution is also extremely appropriate. In this sense, the advanced oxidation process based on the use of semiconductor materials has demonstrated high efficiency in air purification [2-4] or liquid effluents $[5,6]$.

It is well known that photons with appropriate energy promote the excitation of electrons from the valence band to the conduction band in semiconductors. These formed charge carriers electrons at the conduction band and the holes $\left(\mathrm{h}^{+}\right)$at the valence band, in the most interesting cases, can react with $\mathrm{O}_{2}$ and $\mathrm{OH}^{-}$species, respectively, forming free radicals that are able to transform the $\mathrm{NO}_{\mathrm{x}}$ in nitric acid $\left(\mathrm{HNO}_{3}\right)$ [7]. The key reactions considering the titanium dioxide $\left(\mathrm{TiO}_{2}\right)$ material, one of the most used semiconductors in photocatalysis field due to its remarkable properties such as the strong oxidation ability, low-price, non-toxicity and chemical inertness, [8], are described through Eq. (1)-(3) [9].

$\mathrm{NO}+2 \mathrm{OH}^{\cdot} \rightarrow 2 \mathrm{NO}_{2}+\mathrm{H}_{2} \mathrm{O}$

$\mathrm{NO}_{2}+\mathrm{OH}^{\cdot} \rightarrow \mathrm{NO}_{3}^{-}+\mathrm{H}^{+}$

$\mathrm{NO}+\mathrm{O}_{2}^{-} \rightarrow \mathrm{NO}_{3}^{-}$

$\mathrm{O}_{2}$ and $\mathrm{OH}^{-}$species required in the above equations are abundantly available in the atmosphere. Consequently, the immobilization of photocatalysts over different external surfaces of the built environment, such as pavements, roofs, tiles, glass, among others, which are subjected to weather (humidity, rain and sunlight), represent a good strategy to sustainably mitigate air pollution. In particular,

\footnotetext{
* Corresponding author.

E-mail addresses: iran_gomes@hotmail.com (I.G.d. Rocha Segundo), salmon.landi@ifgoiano.edu.br (S. Landi Jr.), sergiooliveira-7@live.com.pt (S.M.B. Oliveira), efreitas@civil.uminho.pt (E.F.d. Freitas), carneiro@fisica.uminho.pt (J.A.O. Carneiro).
} 
photocatalytic pavements have received considerable attention because of their huge occupied area and vicinity to the gases released by vehicles. Moreover, the road pavements are mostly made of asphalt mixtures. The generated species on the photocatalytic surface are highly reactive and non-selective, the degradation of oils, frequently found on roadways, may also occur contributing to the improvement of road safety. In cement-based materials, the photocatalytic capability is also promoted in order to guarantee anti-microbiological effects, destructing harmful bacteria/fungi beside the self-cleaning and de-pollution of NOx and Volatile Organic Compounds (VOC's) [10-12].

One of the most recent concerns of the literature review about photocatalytic materials regards experimental techniques to promote $\mathrm{TiO}_{2}$ semiconductor doping with different materials in order to decrease its band gap, bringing the excitation energy to the visible range of the electromagnetic spectrum [13]. In asphalt mixtures, the application of La-doped [3] and Ce-doped [4] $\mathrm{TiO}_{2}$ nanoparticles prepared by ultrasonic assisted sol-gel and $\mathrm{ZnO}$ by spraying coating, to create a superhydrophobic surface [14], was evaluated. Nevertheless, to benefit of $\mathrm{TiO}_{2}$ doping, it is important to evaluate the immobilization degree of the semiconductor and its mechanical influence in the asphalt mixtures to assure an acceptable time duration of the effect of the technique adopted.

Three main techniques used to produce photocatalytic asphalt mixtures can be highlighted: (i) spraying coating via an aqueous solution of semiconductors applied over the surface of the material (after compaction); (ii) bulk incorporation (during the mix); (iii) bitumen modification. The first technique is the most efficient and uses less amount of semiconductor material, nevertheless it still is important to confirm and guaranty the efficiency of semiconductor immobilization on the materials surface. This method did not provide mechanical deterioration analyzed by Indirect Tensile Strength after water conditioning [14]. The second technique probably guarantees the best immobilization. This technique can impact the performance of the pavements. The literature showed this concern in cement-based materials $[15,16]$, however this analysis is not common in asphalt mixtures. The last technique provides a new capability of self-healing by closing the micro-cracks of the pavements in service [17] and avoids/reduces the UV light ageing [18]. The results of previous investigations show good efficiencies of pollutants removal from the atmosphere by using spraying technique and bulk incorporation of $\mathrm{TiO}_{2}$. Nonetheless, they evidenced problems in keeping the semiconductors on the pavement $[19,20]$. The immobilization of the semiconductors can be affected by traffic wearing [14] and mostly by environment issues, like rain [19].

In the literature, only some initial results related with the mechanical characteristics of asphalt mixtures composed by nanomaterials could be found. Most of the authors use the technique of bitumen modification. The bulk incorporation technique was rarely evaluated [20]. The resistance to permanent deformation and fatigue life can be improved adding $5 \%$ nano- $\mathrm{TiO}_{2}$ and $2 \%$ nano-SiO $\mathrm{S}_{2}$ by bitumen modification. Beyond these characteristics, the bitumen modification with nanoclay can improve the aging resistance [21]. The best content of nanoclay was $2 \%$ taking into account the mechanical behaviour of asphalt mixtures [22].

Therefore, the main goals of this work are to assess the immobilization of $\mathrm{TiO}_{2}$ nanoparticles due to traffic and weathering, by using two experimental techniques (spraying coating and bulk incorporation), and to analyse the mechanical behaviour of asphalt mixtures functionalized by bulk incorporation. In a first phase, the influence of $\mathrm{TiO}_{2}$ nanoparticles on the mechanical properties for the bulk incorporation technique was studied due to the possibility of changing the mechanical behaviour. Then, for the spraying coating, the effects of temperature and spraying rate in the immobilization of the nanomaterials were investigated. Lastly, for both techniques, the influence of traffic and water was analysed by simulating traffic wear (abrasion) and rain.

\section{Materials and samples preparation}

In this research AC 14 surf 35/50 asphalt mixtures were formulated by the Marshall Method, using $92 \%$ of granite aggregates, $3 \%$ of limestone filler and $5 \%$ of asphalt binder in weight of the mixture, aiming $4 \%$ of voids content. The binder, Cepsa ${ }^{\circledR} 35 / 50$, was characterized by: i) Penetration of $30 \times 10^{-1} \mathrm{~mm}$ (EN 1426/2015); ii) Brookfield viscosity of $391 \mathrm{cP}$ at $150{ }^{\circ} \mathrm{C}$ (EN 13302/2010) and iii) Softening Point of $56^{\circ} \mathrm{C}$ (EN 1427/2015). The aggregate composition of the mixtures was: i) limestone filler: $3 \%$; ii) $0 / 4 \mathrm{~mm}$ : $41 \%$; iii) $4 / 8 \mathrm{~mm}$ : $12 \%$ and iv) $6 / 14 \mathrm{~mm}: 44 \%$.

In order to functionalize the asphalt mixtures, the semiconductor nano- $\mathrm{TiO}_{2}$ by Quimidroga ( $\mathrm{TiO}_{2} \mathrm{P} 25: 80 \%$ anatase and $20 \%$ rutile) was used. Its purity is higher than $99.5 \%$ and the particle size is of about 23 to $28 \mathrm{~nm}$ [13]. The band gap of $\mathrm{TiO}_{2}$ was $3.20 \pm 0.03 \mathrm{eV}$, corresponding to the region of UV-A light. It was calculated using the Kubelka-Munk equation obtained from the diffuse reflectance spectrum $[23,24]$.

The asphalt mixes were prepared following the standard EN 131081. The samples were compacted in two geometries: cylindrical to carry out the water sensitivity test (EN 12697-12) and prismatic slabs to assess the photocatalytic efficiency and to carry out mechanical characteristics tests, such as fatigue resistance (AASTHO TP 8-94), stiffness Modulus (EN 12697-26) and permanent deformation resistance (NP 12967-22).

Two techniques were adopted in order to obtain the photocatalytic asphalt mixtures: spraying coating (after compaction) and bulk incorporation (during mix). The first one consisted of spraying at the surface of the asphalt sample an aqueous solution of nano- $\mathrm{TiO}_{2}(4 \mathrm{~g} / \mathrm{L})$ at $\mathrm{pH} 8$ with an atmospheric air compressor at a distance of about $20 \mathrm{~cm}$ during $30 \mathrm{~s}$, being the speed of the aqueous solution jet set at $100 \mathrm{~mL} / \mathrm{min}[14,20]$. The substrate temperatures during spraying were: room temperature (RT), $60^{\circ} \mathrm{C}$ (both considering an application during the use of the pavements), $100{ }^{\circ} \mathrm{C}$ and $140{ }^{\circ} \mathrm{C}$ (both considering the application during paving and compaction). Three spraying ratios were evaluated: 4,8 and $16 \mathrm{~mL} / \mathrm{cm}^{2}$, according to the last studies [14,20,25]. The second technique, by bulk incorporation, consisted of partially replacing the filler with $3 \%$ and $6 \%$ of $\mathrm{TiO}_{2}$ in mass of the bitumen [20], without granulometric changes.

In order to assess the photocatalytic efficiency, small cylindrical samples $(3.6 \mathrm{~cm}$ diameter and $1.0 \mathrm{~cm}$ height) were drilled from the prismatic slabs and then sprayed with the nano- $\mathrm{TiO}_{2}$ aqueous solution. The lateral of most of the samples was covered with bitumen to eliminate the effect of the granulates cut on the photocatalytic efficiency test results.

The samples were identified by characters representing the type of functionalization, the percentage of $\mathrm{TiO}_{2}$, the spraying rate, the temperature, the percentage of abrasion and the rain simulation. The code of the samples starts by C, BI or SC to indicate the control samples, the functionalized samples by bulk incorporation or the functionalized samples by spraying coating, respectively. The samples which laterals were not covered with bitumen were designated by WC (without covering). The samples submitted to wearing and rain simulation were identified by the percentage of abrasion (e.g. $0.5 \%$ means $0.5 \%$ of a superficial abrasion) and by W (water simulation), respectively. By bulk incorporation, the samples were composed by 3 and $6 \%$ of $\mathrm{TiO}_{2}$, indicated by $3 \% \mathrm{~T}$ and $6 \% \mathrm{~T}$, respectively. By spraying coating, the samples were functionalized at 3 rates, 4,8 and $16 \mathrm{~mL} / \mathrm{cm}^{2}$, indicated by $4 \mathrm{R}, 8 \mathrm{R}$ and $16 \mathrm{R}$. The four temperatures of the asphaltic substrate during the spraying: room temperature, 60,100 and $140{ }^{\circ} \mathrm{C}$, were identified by RT, 60, 100 and 140. For example, the sample SC_8R_140_1\%_W was functionalized by spraying coating using the rate $8 \mathrm{~mL} / \mathrm{cm}^{2}$ at $140{ }^{\circ} \mathrm{C}$ and submitted to $1 \%$ of abrasion and also rain simulation. The photocatalytic efficiency was evaluated in all samples, however only samples C, BI_3\%T and BI_6\%T were evaluated through mechanical performance. 


\section{Methods}

\subsection{Water sensitivity}

In order to analyse the moisture resistance of asphalt mixtures with and without nanoparticles, the Indirect Tensile Strength Ratio (ITSR) test was carried out. Following the standard EN 12697-12, two groups of each mixture is produced considering their volumetric properties. One group of samples was immersed in water at $40{ }^{\circ} \mathrm{C}$ during $72 \mathrm{~h}$, the other one was kept out of the conditioning. After this process, all samples were placed in a chamber at $15^{\circ} \mathrm{C}$ during $2 \mathrm{~h}$ to test them under indirect tensile Strength. The ratio between the wet samples (ITSw) and the dry samples (ITSd) was calculated and defined as ITSR.

\subsection{Permanent deformation}

The permanent deformation of the asphalt mixtures was assessed by the Wheel Tracking Test (WTT) (EN 12697-22). Therefore, for each mixture, two prismatic slabs $\left(30 \times 30 \times 4.0 \mathrm{~cm}^{3}\right)$ were tested up to 10,000 cycles of a $700 \mathrm{~N}$ wheel at $0.44 \mathrm{~Hz}$ and $60^{\circ} \mathrm{C}$. The curve deformation versus cycle and the maximum rutting of the asphalt mixtures with and without $\mathrm{TiO}_{2}$ will be compared.

\subsection{Stiffness modulus}

This property, used for pavement design, was assessed by the fourpoint bending test configuration (EN 12697-26) for the frequencies 0.1, $0.2,0.5,1,2,5,8$ and $10 \mathrm{~Hz}$ at $20^{\circ} \mathrm{C}$. The graph Stiffness versus Frequency $(\mathrm{Hz})$ of the asphalt mixtures with and without $\mathrm{TiO}_{2}$ will be compared.

\subsection{Fatigue test}

This test aimed to measure the capacity of the mixtures to resist to cyclic loading through the four-point bending test procedure (EN 12697-24). In this test, samples at $20^{\circ} \mathrm{C}$ are submitted to sinusoidal loading at $10 \mathrm{~Hz}$, in strain control. When the stiffness modulus of the asphalt mixture samples reaches half of their initial value, theoretically, fracture occurs and the test stops. The fatigue resistance of the sample corresponds to the number of loading cycles at the end of the test. The graph strain level versus number of cycles will be presented.

\subsection{Photocatalytic efficiency}

The photocatalytic efficiency tests are based on the measurement of the degradation of Rhodamine $\mathrm{B}(\mathrm{RhB})$ as a function of time irradiation with an artificial sunlight [14,20]. Therefore, each asphalt mixture sample was inserted into a beaker and completely immersed with $20 \mathrm{~mL}$ of RhB aqueous solution ( $5 \mathrm{ppm}$ ). After $3 \mathrm{~h}$ in dark condition (adsorption), the samples were irradiated during $8 \mathrm{~h}$ a light (300 W - OSRAM UltraVitalux lamp, $11 \mathrm{~W} / \mathrm{m}^{2}$ of UV light measured by Quantum Photo Radiometer HD9021 Delta Padova). All the beakers were closed with a transparent plastic film with at least $90 \%$ of transmittance in the wavelength range between 292 and $900 \mathrm{~nm}$ in order to avoid the evaporation of RhB. The photocatalytic efficiency (Eq. (4)) was calculated using the Beer-Lambert law [20]. For this test, 3 samples were used and the average of the result will be presented.

$\Phi(\%)=\left(\frac{A_{o}-A}{A_{o}}\right) \times 100$

where $\Phi$ is the photocatalytic efficiency, A and $A_{0}$ represent the maximum absorbance of RhB $(553 \mathrm{~nm})$ solution for time "t" and $0 \mathrm{~h}$ after irradiation, respectively, which were measured using a Shimadzu 3101 PC spectrophotometer.

\subsection{Traffic simulation}

To assess the impact of the traffic wearing, i.e. the semiconductors' removal by traffic, mechanical abrasion was carried out homogeneously over the asphalt mixtures' surface using a metallic wire brush disc (at $450 \mathrm{rpm}$ ), conducting to 3 mass loss levels: $0,5 \%, 1 \%, 2 \%$ [14].

\subsection{Rain simulation}

In order to assess semiconductors' removal by water, each sample was submitted to rain simulation through a water flow of $100 \mathrm{~mL} / \mathrm{min}$ during $5 \mathrm{~h}$. The total water volume corresponds in average to one year of rain in Portugal.

\section{Results and discussions}

\subsection{Performance of the asphalt mixtures}

\subsubsection{Water sensitivity}

The results of ITS and water sensitivity (ITSR) of the asphalt mixtures composed by $\mathrm{TiO}_{2}$ incorporated in volume are presented in Fig. 1a (3.7\% average air voids). The ITS and the ITSR were affected by the content of $\mathrm{TiO}_{2}$. The lowest content of $\mathrm{TiO}_{2}$ (BI_3\% $)$ led to lower values of these parameters, while the highest content (BI_3\%T) led to higher ITS and lower ITSR. It can be concluded that the use of $\mathrm{TiO}_{2}$ by bulk incorporation reduces the water resistance of the asphalt mixture. However, all the results of ITSR are higher than $80 \%$, the minimum value requested for this parameter of the water sensitivity of asphalt mixtures in Portugal.

\subsubsection{Permanent deformation}

The permanent deformation test has a high importance in countries with hot climate where this phenomenon manifests itself with large significance. The permanent deformation was affected by the content of $\mathrm{TiO}_{2}$ (Fig. 1b). On the one hand, the lowest content of $\mathrm{TiO}_{2}(3 \%)$ conducted to a slightly higher deformation $(7.5 \mathrm{~mm})$ than the conventional mixture $(6.8 \mathrm{~mm})$. On the other hand, the highest content of $\mathrm{TiO}_{2}$ (6\%) conducted to better results of this parameter $(4.95 \mathrm{~mm})$, reducing the permanent deformation.

\subsubsection{Stiffness modulus}

The stiffness of the asphalt mixture was also influenced by the content of $\mathrm{TiO}_{2}$ (Fig. 2a). While the lowest content of $\mathrm{TiO}_{2}$ (3\%) conducted to a lower stiffness than the conventional mixture, the highest content (6\%) conducted to similar stiffness moduli. This performance is in accordance with the results found the permanent deformation.

\subsubsection{Fatigue resistance}

Fig. $2 \mathrm{~b}$ presents the fatigue curve (number of cycle versus applied strain) determined for the 3 asphalt mixtures. Good determination coefficients $\left(\mathrm{R}^{2}\right)$ were achieved, higher than 0.85 . The asphalt mixture composed by $3 \%$ of nano- $\mathrm{TiO}_{2}$ had the same behaviour as the conventional asphalt mixture, the fatigue curves are overlapped. The fatigue resistance of the asphalt mixture was affected only when $6 \%$ of nano- $\mathrm{TiO}_{2}$ was used, reducing the fatigue resistance under very low strain, as can be seen through the higher slope.

\subsection{Photocatalytic efficiency}

\subsubsection{Evaluation of substrate temperature during application}

The dependence of the substrate temperatures (RT, $60{ }^{\circ} \mathrm{C}, 100{ }^{\circ} \mathrm{C}$ and $140{ }^{\circ} \mathrm{C}$ ) on the photocatalytic efficiency of the samples functionalized with $\mathrm{TiO}_{2}$ by spraying is illustrated in Fig. 3. There was no substantial difference in the photocatalytic performance of the samples at different temperatures. The results obtained for the samples with lateral surfaces not covered with bitumen (Fig. 3a) suggest the increase of the 
a)

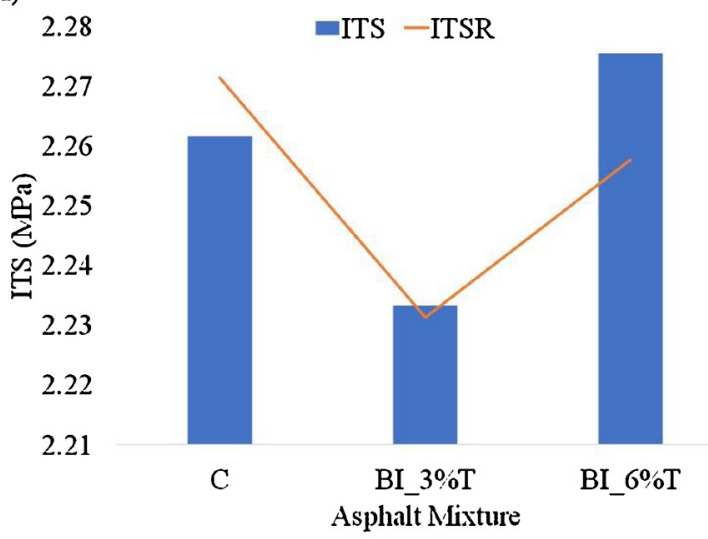

90

88

86

84

82

80

78

76

b)

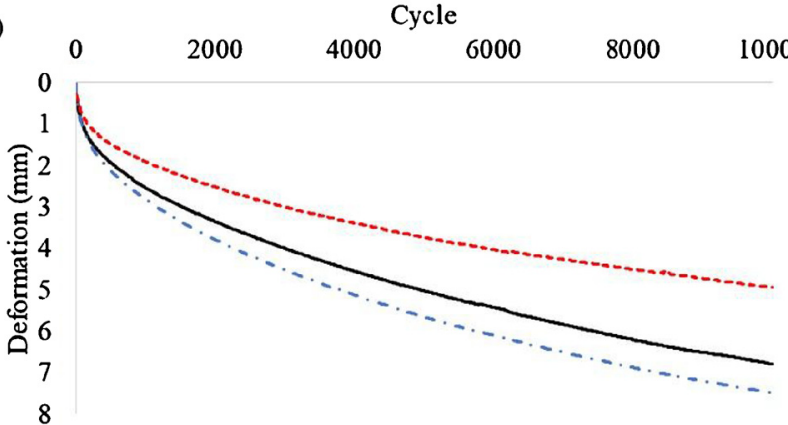

-C ----BI_6\% $-\cdot-$ BI_3\%T

Fig. 1. a) Water Sensitivity; b) Permanent Deformation Results.

a) 10000

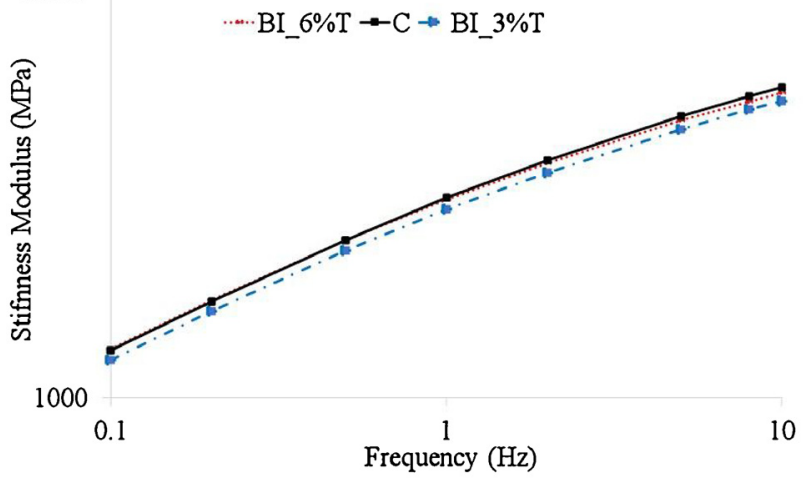

b)

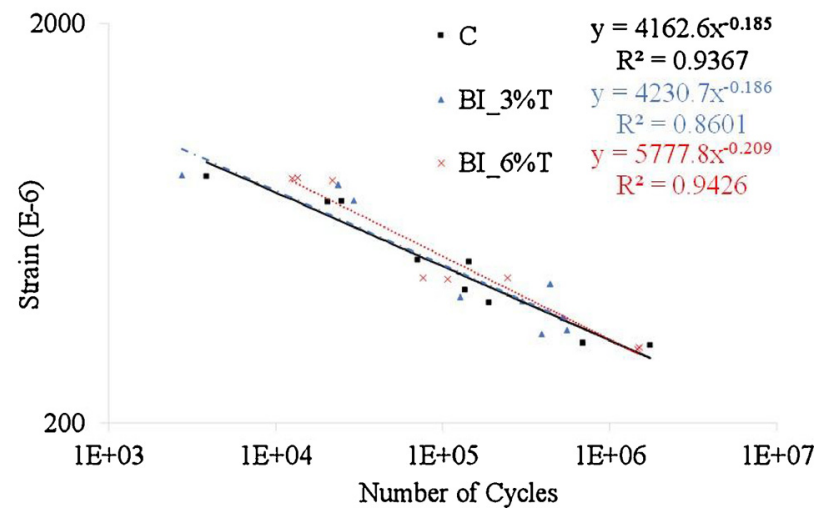

Fig. 2. a) Stiffness Modulus; b) Fatigue Resistance.
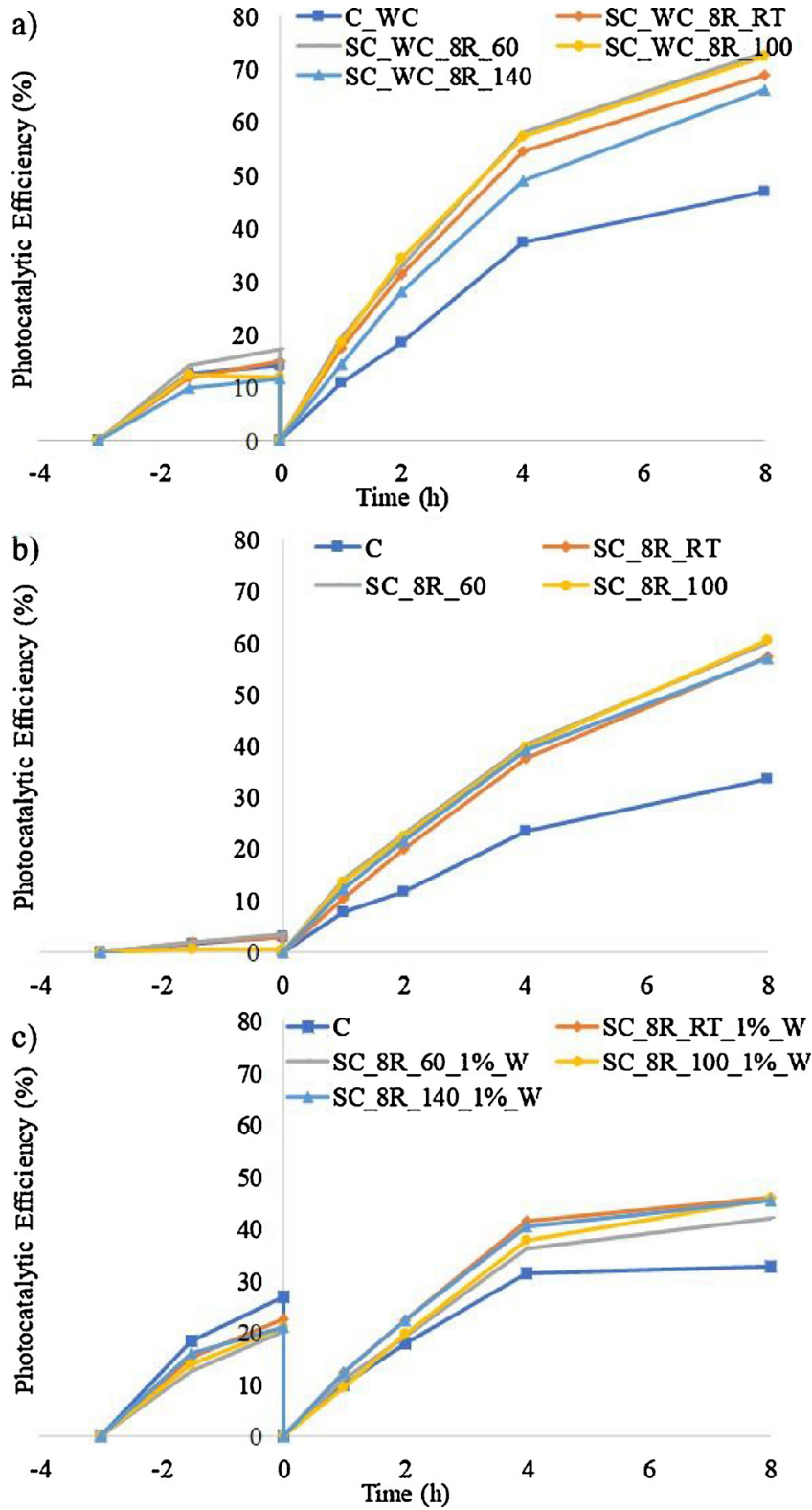

Fig. 3. Photocatalytic Efficiency for Different Temperatures: a) before abrasion and without lateral covering; b) before abrasion and with lateral covering; c) after $1 \%$ superficial abrasion and rain simulation.

photocatalytic efficiency due to the contact of the aggregates with RhB dye solution and to light exposition. The same situation, but with the samples laterals covered with bitumen lead to a decrease of the photocatalytic efficiency (Fig. 3b). After covering the laterals of the control samples, it decreased $29 \%$. In average, a reduction of $17 \%$ was found for the functionalized samples. Thus, in order to eliminate the lateral effect of the exposed aggregates, all the experiments were carried out with samples covered with bitumen, except in their superior faces (i.e. the functionalized faces). In this sense, the selection of aggregates seems important since their constitution can facilitate the photocatalytic process together with $\mathrm{TiO}_{2}$ mainly for oil/grease degradation in order or reduce road accidents caused by contamination of these materials.

After the abrasion and weathering processes with $1 \%$ of superficial abrasion, this trend was the same (Fig. 3c). However, in this case there was a decrease of about $10 \%$ on the photocatalytic efficiency compared to the samples that did not undergo the abrasion process, which probably is related to the removal of photocatalytic materials on the 

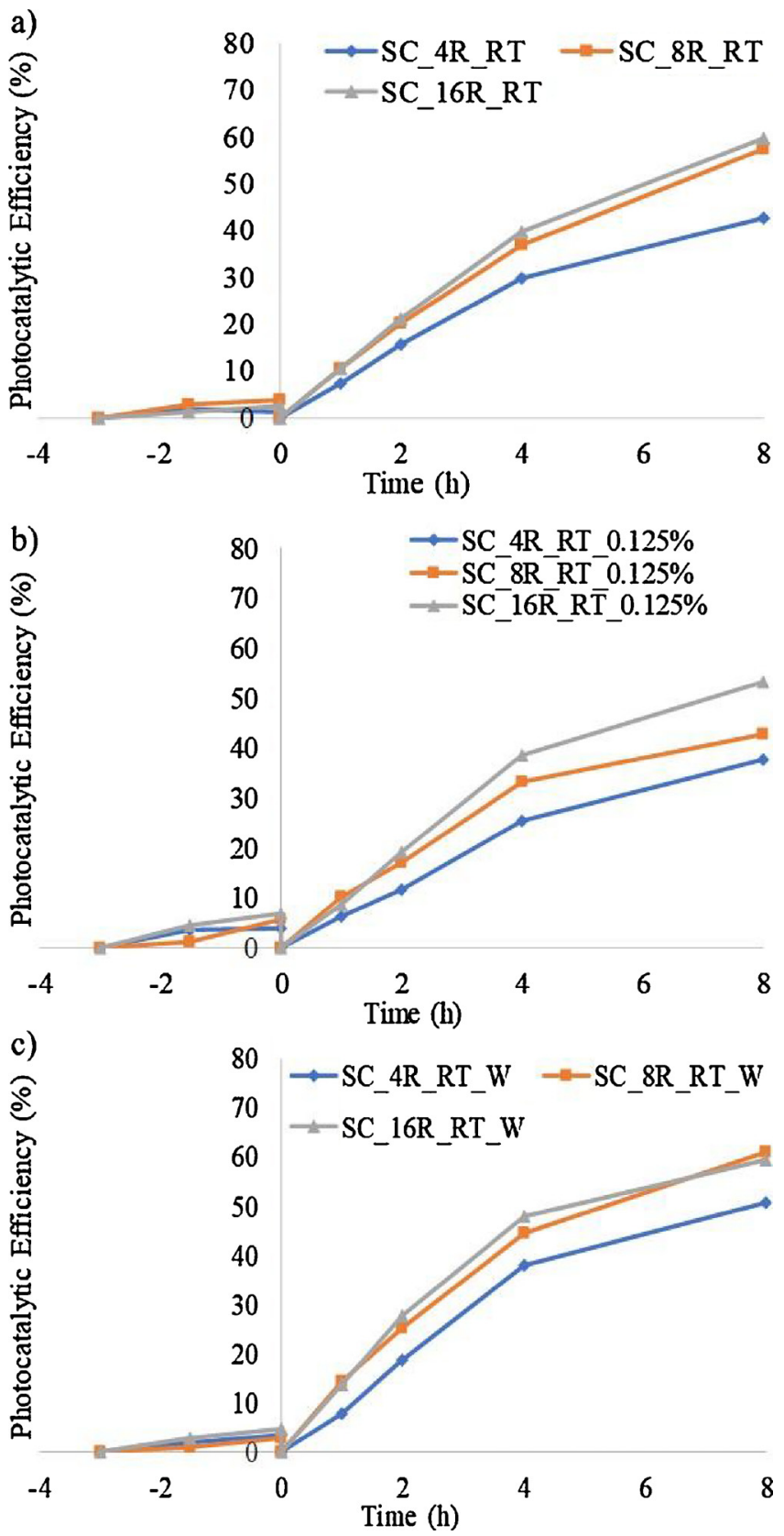

Fig. 4. Photocatalytic Efficiency for Different Spraying Rates: a) before abrasion; b) after $0.125 \%$ of a superficial abrasion; c) after rain simulation.

coated surfaces. From these results it can be concluded that, under the severe abrasion and the rain simulation processes, the functionalization of the pavements at room temperature is feasible. Therefore, the spraying technique may be applied at anytime of the pavement life, including construction and use. Also, the reapplication of the technique is possible after the removal of the nanomaterials.

\subsubsection{Evaluation of substrate spraying rate}

To evaluate the spraying ratio effect, three rates were selected and applied at room temperature: 4,8 and $16 \mathrm{~mL} / \mathrm{cm}^{2}$. Prior to abrasion process, the most effective rates were 8 and $16 \mathrm{~mL} / \mathrm{cm}^{2}$ which lead to a photocatalytic efficiency of about $60 \%$ (Fig. 4a). Under abrasion of $0.125 \%$, the best rates were in ascending order: $4 ; 8 ; 16 \mathrm{~mL} / \mathrm{cm}^{2}$ (Fig. 4b). After rain simulation, also the most effective rates were 8 and $16 \mathrm{~mL} / \mathrm{cm}^{2}$ (Fig. $4 \mathrm{c}$ ). The other tests were carried out using the intermediate rate $\left(8 \mathrm{~mL} / \mathrm{cm}^{2}\right)$ due to the similarity under rain simulation and before abrasion. Also, the rate uses half of the volume per $\mathrm{cm}^{2}$, being more economic than the rate of $16 \mathrm{~mL} / \mathrm{cm}^{2}$.

\subsubsection{Study of the fixation of the nanomaterials}

The study of the fixation was carried out for 6 situations (Fig. 5): a) before abrasion; b) after rain simulation; c) with $0.5 \%$ of a superficial abrasion; d) with $0.5 \%$ of superficial abrasion and after rain simulation; e) with $2 \%$ of superficial abrasion; and f) with $2 \%$ of superficial abrasion and after rain simulation.

The photocatalytic efficiency was much higher for the spraying coating than the functionalization by bulk incorporation before abrasion (Fig. 5a and b). Probably the low efficiency of these samples functionalized by bulk incorporation was due to the low content of $\mathrm{TiO}_{2}$ over the surface (i.e. exposed to the light) and also because the superficial bitumen film covers the nanoparticles.

However, after the superficial abrasion, the photocatalytic efficiency of the sprayed samples decreased in opposition to the bulk incorporation process (Fig. 5c-f). For example, the photocatalytic efficiency of BI_3\%T increased from 32\% (Fig. 5a) to about $40 \%$ and $55 \%$ with $0.5 \%$ and $2 \%$ of abrasion, respectively (Fig. $5 \mathrm{c}$ and e). For the BI_6\%T, it was registered an increase of $4 \%$ and $41 \%$ under the same levels of abrasion. After the abrasion, the $\mathrm{TiO}_{2}$ applied by the spraying technique was removed from the surface while by bulk incorporation it was more exposed. This effect is more important for higher levels of abrasion. In view of this, it is essential to evaluate the impact of the abrasion on photocatalytic materials which will be submitted to this process in their life time.

Contrarily to the expectations, which were the achievement of better results for higher percentages of nano- $\mathrm{TiO}_{2}$, for bulk incorporation, the highest photocatalytic efficiency was found for the samples with lower content of $\mathrm{TiO}_{2}$ (BI_3\%T). A possible explanation is that higher percentages can result in photocatalytic particle's agglomeration, thereby decreasing its surface area and consequently the photocatalytic efficiency. Additionally, the photocatalytic efficiency was not affected under rain simulation (Fig. 5b, d and f). Also, the spraying coating technique lead to a very high photocatalytic efficiency, including under the rain simulation. However, when this process is preceded by abrasion, the $\mathrm{TiO}_{2}$ nanoparticles are removed leading to lower efficiency. Therefore, the impact of rain simulation is very reduced since it did not remove the particles.

In practice, road pavements are submitted to traffic abrasion mostly on the wheel tracks. The other areas of the traffic lanes and also the shoulders are mostly submitted to weathering. Taking into account the low impact on photocatalytic efficiency of the rain, it is expected a high performance of both techniques on field since the area submitted to the abrasion is significantly lower than the total area of the pavement.

\section{Conclusions}

The aim of this research was the analysis of the impact of photocatalytic asphalt mixtures functionalized by bulk incorporation on mechanical performance and by both bulk incorporation and spraying coating on photocatalytic efficiency considering the following factors: application temperature, traffic (wearing) and climate (weathering). Based on the results of this research, the following conclusions can be drawn:

- For bulk incorporation of nano- $\mathrm{TiO}_{2}$, the moisture resistance was reduced but respected the limit by the Portuguese specification for top layer asphalt mixtures. On one hand, the higher content of $\mathrm{TiO}_{2}$ (6\%) improved the permanent deformation, had similar results of stiffness modulus and reduced the fatigue resistance under very low strain, when compared with the conventional mixture. On the other hand, when compared with the conventional mixture, the lower content of nano- $\mathrm{TiO}_{2}(3 \%)$ increased slightly the permanent deformation, conducted to a lower stiffness, but kept the fatigue 

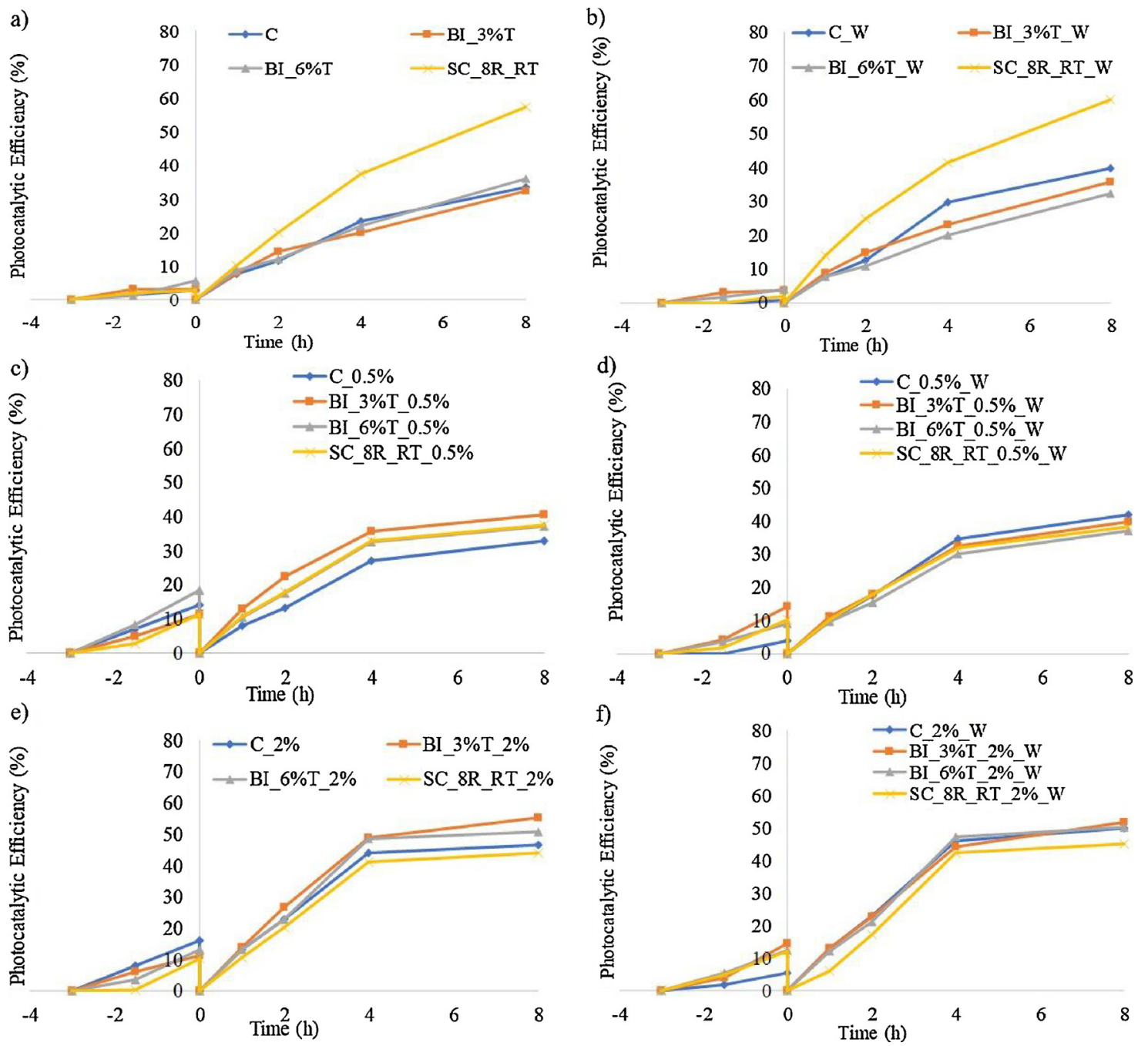

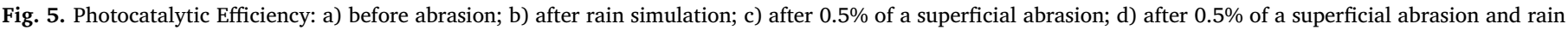
simulation; e) after $2 \%$ of superficial abrasion; f) after $2 \%$ of superficial abrasion and rain simulation.

resistance.

- The granitic nature of the aggregates provided an increase of the photocatalytic efficiency. Thus, the selection of aggregates is important since it can improve the photocatalytic process together with $\mathrm{TiO}_{2}$.

- The temperature of the substrate had no influence on the photocatalytic results before and after the abrasion process used to simulate traffic wearing. Therefore, the coating technique can be used at the construction or paving phase and also at any time of the pavement's use.

- The most effective spraying rates were 8 and $16 \mathrm{~mL} / \mathrm{cm}^{2}$ before the abrasion and after rain simulation. Under abrasion of $0.125 \%$, the best rates were in ascending order $4 \mathrm{~mL} / \mathrm{cm}^{2}<8 \mathrm{~mL} / \mathrm{cm}^{2}<16 \mathrm{~mL}$ / $\mathrm{cm}^{2}$.

- The photocatalytic efficiency was much higher for the spraying coating than the functionalization by bulk incorporation before abrasion. The low efficiency by bulk incorporation was probably due to the low content of $\mathrm{TiO}_{2}$ over the surface of samples.

- Only under rain simulation, the photocatalytic efficiency was not affected. The spraying coating has a very high photocatalytic efficiency including after this process.

- After abrasion, the photocatalytic efficiency of sprayed samples was highly reduced, while for bulk incorporation samples it increased with the level of abrasion.

- The rain simulation in combination with abrasion washes the surface, removing the nanoparticles which were not immobilized.

In this work the main methodological issue was the simulation of the traffic wearing through an abrasion process. For big samples there are some recognized wearing techniques, however for small samples a traffic wearing procedure needs to be developed and validated. Nevertheless, the procedure adopted for this study seemed adequate and provided good results.

With these results seems acceptable to forecast a good performance of the photocatalytic road surfaces on field. The surface of road pavements is submitted to traffic wearing mostly in the wheel tracks. It represents a reduced percentage of the total area of the surface. In view of the low effect of rain on the photocatalytic efficiency, it is expected a good performance of the spraying coating technique, less expensive. The ideal solution would be the combination of both techniques, with negligible impact on mechanical performance, however it requires a cost-benefit analysis.

\section{Acknowledgments}

This work was partially financed by FCT-Fundação para a Ciência e a Tecnologia-under the project PTDC/FIS/120412/2010: "Nanobased concepts for Innovative \& Eco-sustainable constructive material's surfaces" and project PEst-OE/ECI/UI4047/2014. 


\section{References}

[1] M. Martin, S. Leonid, R. Tomáš, Š. Jan, K. Jaroslav, K. Mariana, J. Michaela, P. František, P. Gustav, Anatase $\mathrm{TiO}_{2}$ nanotube arrays and titania films on titanium mesh for photocatalytic NOx removal and water cleaning, Catal. Today 287 (2017) 59-64, https://doi.org/10.1016/j.cattod.2016.10.011.

[2] M. Faraldos, R. Kropp, M.A. Anderson, K. Sobolev, Photocatalytic hydrophobic concrete coatings to combat air pollution, Catal. Today 259 (2016) 228-236 https://doi.org/10.1016/j.cattod.2015.07.025.

[3] B. Tang, X. Liu, W. Huang, X. Cao, Preparation of La-doped nanometer TiO2 and its application for NO removal on asphalt concrete, Road Mater. Pavement Des. 18 (2017) 43-53, https://doi.org/10.1080/14680629.2017.1329860.

[4] X. Cao, X. Yang, H. Li, W. Huang, X. Liu, Investigation of Ce- $\mathrm{TiO}_{2}$ photocatalyst and its application in asphalt- based specimens for NO degradation, Constr. Build. Mater. 148 (2017) 824-832, https://doi.org/10.1016/j.conbuildmat.2017.05.095.

[5] A.B. Baranda, O. Fundazuri, I. Martínez De Marañón, Photodegradation of several triazidic and organophosphorus pesticides in water by pulsed light technology, J. Photochem. Photobiol. A Chem. 286 (2014) 29-39, https://doi.org/10.1016/j. jphotochem.2014.03.015.

[6] S. Landi, J. Carneiro, S. Ferdov, A.M. Fonseca, I.C. Neves, M. Ferreira, P. Parpot, O.S.G.P. Soares, M.F.R. Pereira, Photocatalytic degradation of rhodamine B dye by cotton textile coated with $\mathrm{SiO}_{2}-\mathrm{TiO}_{2}$ and $\mathrm{SiO}_{2}-\mathrm{TiO}_{2}-\mathrm{HY}$ composites, J. Photochem. Photobiol. A Chem. 346 (2017) 60-69, https://doi.org/10.1016/j.jphotochem. 2017.05.047.

[7] A. Mills, S. Elouali, The nitric oxide ISO photocatalytic reactor system: measurement of NOx removal activity and capacity, J. Photochem. Photobiol. A Chem. 305 (2015) 29-36, https://doi.org/10.1016/j.jphotochem.2015.03.002.

[8] I. Papailias, N. Todorova, T. Giannakopoulou, J. Yu, D. Dimotikali, C. Trapalis, Photocatalytic activity of modified $g-\mathrm{C}_{3} \mathrm{~N}_{4} / \mathrm{TiO}_{2}$ nanocomposites for NOx removal, Catal. Today 280 (2017) 37-44, https://doi.org/10.1016/j.cattod.2016.06.032.

[9] A. Fujishima, X. Zhang, D.A. Tryk, $\mathrm{TiO}_{2}$ photocatalysis and related surface phenomena, Surf. Sci. Rep. 63 (2008) 515-582, https://doi.org/10.1016/j.surfrep. 2008.10.001.

[10] N.S. Allen, M. Edge, J. Verran, J. Stratton, J. Maltby, C. Bygott, Photocatalytic titania based surfaces: environmental benefits, in, Polym. Degrad. Stab. (2008) 1632-1646, https://doi.org/10.1016/j.polymdegradstab.2008.04.015.

[11] N.S. Allen, M. Edge, J. Verran, L. Caballero, C. Abrusci, J. Stratton, J. Maltby, C. Bygott, Photocatalytic surfaces: environmental benefits of nanotitania, Open Mater. Sci. J. 3 (2009) 6-27 doi:1874-088X/09.

[12] N. Allen, E. Michele, V. Joanne, S. John, M. Julie, B. Claire, N. Allen, M. Edge, J. Verran, J. Stratton, J. Maltby, C. Bygott, Photocatalytic surfaces: antipollution and antimicrobial effects, Nanotechnology, 2nd ed., American Cancer Society, 2010, pp. 17-50, https://doi.org/10.1002/9783527628155.nanotech011.
[13] J.O. Carneiro, S. Azevedo, F. Fernandes, E. Freitas, M. Pereira, C.J. Tavares, S. Lanceros-Méndez, V. Teixeira, Synthesis of iron-doped $\mathrm{TiO}_{2}$ nanoparticles by ball-milling process: the influence of process parameters on the structural, optical, magnetic, and photocatalytic properties, J. Mater. Sci. 49 (2014) 7476-7488, https://doi.org/10.1007/s10853-014-8453-3.

[14] I. Rocha Segundo, C. Ferreira, E.F. Freitas, J.O. Carneiro, F. Fernandes, S. Landi Júnior, M.F. Costa, Assessment of photocatalytic, superhydrophobic and selfcleaning properties on hot mix asphalts coated with $\mathrm{TiO}_{2}$ and/or $\mathrm{ZnO}$ aqueous solutions, Constr. Build. Mater. 166 (2018) 36-44, https://doi.org/10.1016/j. conbuildmat.2018.01.106.

[15] J.V.S. Melo, G. Trichês, Study of the influence of nano- $\mathrm{TiO}_{2}$ on the properties of Portland cement concrete for application on road surfaces, Road mater, Pavement Des. 0629 (2017) 1-16, https://doi.org/10.1080/14680629.2017.1285811.

[16] M. Smits, D. Huygh, B. Craeye, S. Lenaerts, Effect of process parameters on the photocatalytic soot degradation on self-cleaning cementitious materials, Catal. Today 230 (2014) 250-255, https://doi.org/10.1016/j.cattod.2013.10.001.

[17] J. Qiu, M.F.C. van de Ven, A.A.A. Molenaar, J. Qiu, S. Wu, J. Yu, Investigating the self healing capability of bituminous binders, Road mater, Pavement Des. 10 (2009) 81-94, https://doi.org/10.1080/14680629.2009.9690237.

[18] Z. Chen, H. Zhang, C. Zhu, B. Zhao, Rheological examination of aging in bitumen with inorganic nanoparticles and organic expanded vermiculite, Constr. Build. Mater. 101 (2015) 884-891, https://doi.org/10.1016/j.conbuildmat.2015.10.153.

[19] E. Bocci, L. Riderelli, G. Fava, M. Bocci, Durability of NO oxidation effectiveness of pavement surfaces treated with photocatalytic titanium dioxide, Arab, J. Sci. Eng. (2016) 1-7, https://doi.org/10.1007/s13369-016-2168-5.

[20] J.O.O. Carneiro, S. Azevedo, V. Teixeira, F. Fernandes, E. Freitas, H. Silva, J. Oliveira, Development of photocatalytic asphalt mixtures by the deposition and volumetric incorporation of $\mathrm{TiO}_{2}$ nanoparticles, Constr. Build. Mater. 38 (2013) 594-601, https://doi.org/10.1016/j.conbuildmat.2012.09.005.

[21] H. Taherkhani, R. Bayat, Applied nanomaterials in enhancing the properties of asphalt mixtures., Casp, J. Appl. Sci. Res. 4 (2015).

[22] E. Iskender, Evaluation of mechanical properties of nano-clay modified asphalt mixtures, Meas. J. Int. Meas. Confed. 93 (2016) 359-371, https://doi.org/10.1016/ j.measurement.2016.07.045.

[23] V. Džimbeg-malčić, Ž. Barbarić-mikočević, K. Itrić, Kubelka-munk theory in describing optical properties of paper (I), Teh. Vjesn. 18 (2011) 117-124.

[24] H.G. Hecht, The interpretation of diffuse reflectance spectra, J. Res. Natl. Bur. Stand. Phys. Chem. 80a (1976) 567-583.

[25] I.G. da Rocha Segundo, E.A.L. Dias, F.D.P. Fernandes, E.F. de Freitas, M.F. Costa, J.O. Carneiro, Photocatalytic asphalt pavement: the physicochemical and rheological impact of $\mathrm{TiO}_{2}$ nano/microparticles and $\mathrm{ZnO}$ microparticles onto the bitumen, Road Mater. Pavement Des. (2018), https://doi.org/10.1080/14680629.2018. 1453371. 